\title{
Toxicity of Cellulose Nanocrystals: A Review
}

\author{
Maren Roman \\ Department of Sustainable Biomaterials and Macromolecules \\ and Interfaces Institute, Virginia Tech, Blacksburg, VA
}

\begin{abstract}
Cellulose nanocrystals (CNCs) are a biobased nanomaterial attracting increasing interest for a range of potential applications. This article reviews the current literature on the pulmonary, oral, dermal, and cytotoxicity of CNCs. Current studies of the oral and dermal toxicity of CNCs have shown a lack of adverse health effects, whereas studies of the pulmonary and cytotoxicity have yielded discordant results. Additional studies are needed to support the general conclusion that CNCs are nontoxic on ingestion or contact with the skin and to determine whether CNCs have adverse health effects on inhalation or elicit inflammatory or oxidative stress responses at the cellular level. This review underscores the importance of careful sample characterization and exclusion of interfering factors, such as the presence of endotoxins or toxic chemical impurities, for a detailed understanding of the potential adverse health effects of CNCs by various exposure routes.
\end{abstract}

\section{Introduction}

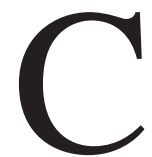

ellulosic nanomaterials are an emerging class of nanomaterials with several desirable properties: they are produced from a renewable starting material at relatively low cost, are biodegradable, biocompatible, and have high water absorption capacity, mechanical strength, and stiffness. Consequently, cellulosic nanomaterials are being studied for a number of potential applications, including polymer nanocomposites, transparent or chiral films, rheology modifiers and hydrogels, drug-delivery vehicles, artificial blood vessels, and wound dressings. ${ }^{1-7}$ However, before a material or technology can be commercialized, its impact on the environment and human health needs to be thoroughly assessed. The literature on cellulosic nanomaterial toxicity has recently been summarized in two review articles covering the use of cellulosic nanomaterials in biomedicine. ${ }^{8,9}$ The present review provides a more in-depth look at the effects of cellulose nanocrystals (CNCs) on human health.

CNCs can be obtained from different starting materials, including tunicin, bacterial cellulose, algal cellulose, wood pulp, bast fibers, cotton linters, and microcrystalline cellulose. ${ }^{10,11}$ Current studies of CNC toxicity have focused on plant fiberderived $\mathrm{CNCs}$, which are shorter and have smaller cross- sectional dimensions than those derived from animal, bacterial, or algal cellulose. Wood-derived CNCs, for example, have average lengths of $100-200 \mathrm{~nm}$ and average cross-sectional dimensions of 3-5 nm (Fig. 1). ${ }^{11,12}$

CNCs are typically prepared by acid hydrolysis of the cellulose starting material. When sulfuric acid is used, the hydroxyl groups on the CNC surface become partially esterified; the resulting sulfate half-esters impart acidic properties to CNCs. With respect to CNCs' effects on human health, their acidic properties might be of minor concern because of the buffering capacity of the human body. Their $\mathrm{pH}$-lowering effect should, however, be considered in cytotoxicity assessments and can altogether be prevented by using the sodium salt form. The $\mathrm{pK}_{\mathrm{a}}$ of the sulfate half-esters on CNCs has been reported as 2.46, which means that CNCs are fully ionized-i.e., have a degree of ionization of $1.00-$ at a $\mathrm{pH}$ of 4.76 and above. ${ }^{13}$ Consequently, sulfate group-bearing CNCs have a negative surface charge at physiological $\mathrm{pH}$ levels, diminished only in the low $\mathrm{pH}$ environment of the stomach. The negative surface charge gives rise to repulsive Coulomb interactions between the CNCs, preventing aggregation due to attractive forces, such as hydrogen bonding. However, because of the abundance of sodium and other cations in body fluids and their charge-shielding effect, aggregation of CNCs in these fluids might nevertheless occur.

Many nanomaterials have been shown to have adverse health effects upon entering the body. ${ }^{14,15}$ Unintentional or coincidental uptake of nanoparticles into the body generally occurs by inhalation, ingestion, or transdermal absorption. In addition, nanoparticles may be present in medications or vaccines administered by injection. Because no studies have yet been published on the parenteral toxicity of $\mathrm{CNCs}$, this literature review focuses on their potential and demonstrated pulmonary, oral, dermal, and cytotoxicity.

\section{Pulmonary Toxicity}

Pulmonary toxicity is the medical term for any adverse health effects that occur when a foreign substance enters the respiratory tract. The respiratory tract has three regions: the nasalpharyngeal-laryngeal (NPL) region, the tracheobronchial region, and the alveolar (gas-exchange) region (Fig. 2). ${ }^{16,17}$ The tracheobronchial region consists of the trachea, which bifurcates into two primary bronchi and further subdivides into secondary bronchi, tertiary bronchi, and bronchioles of progressively smaller diameter. The bronchi and bronchioles are lined by a columnar epithelium (cell lining) of $0.5-5-\mathrm{mm}$ thickness that is covered with a negatively charged mucus layer (isoelectric point $[\mathrm{pI}]=2.72$ ) of approximately neutral $\mathrm{pH} .^{15,18,19}$

In contrast, the walls of the alveoli (microscopic sacs responsible for gas exchange) consist of a single cell layer covered 


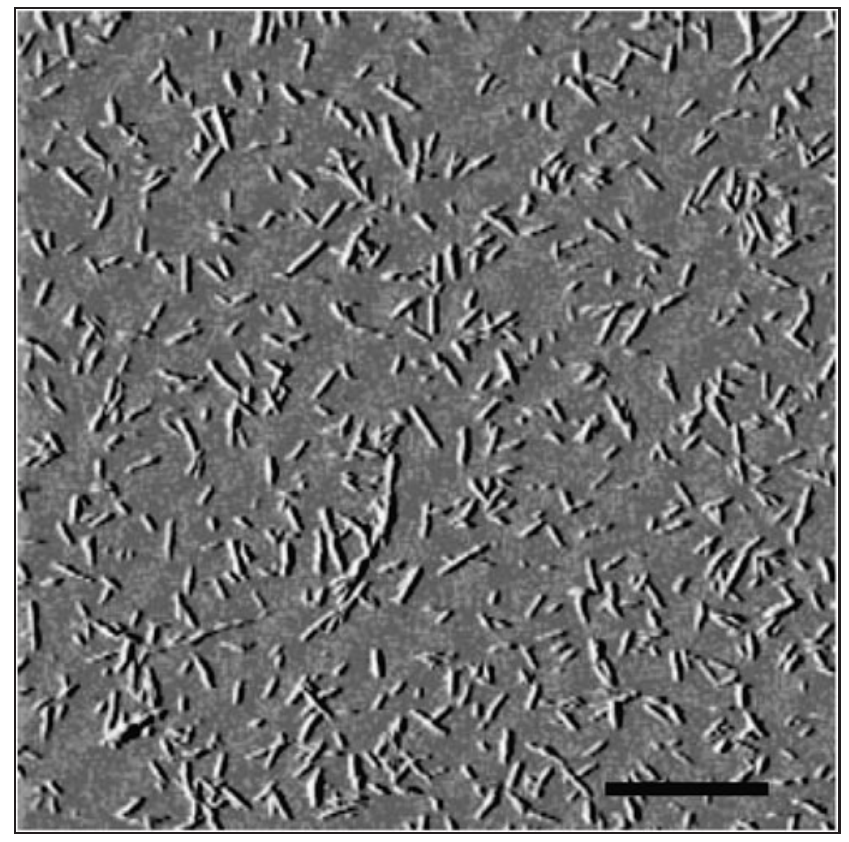

Fig. 1. Wood-derived cellulose nanocrystals (scale bar: $1 \mu \mathrm{m}$ ). Adapted with permission from Roman M. Cellulose nanocrystals.jpg (Wikimedia Commons)

only by a thin $(\sim 0.1 \mu \mathrm{m})$ liquid layer. ${ }^{20}$ A mathematical model by the International Commission on Radiological Protection predicts that very small $(\sim 1 \mathrm{~nm})$ and very large $(\sim 10 \mu \mathrm{m})$ inhaled particles are deposited primarily in the NPL region, whereas particles of about $5 \mathrm{~nm}$ in size are deposited approximately equally in all three regions, and particles of about $20 \mathrm{~nm}$ in size are deposited primarily $(\sim 50 \%)$ in the alveolar region (Fig. 2). ${ }^{16,}{ }^{17}$ Particles that are deposited in the NPL and tracheobronchial regions are primarily cleared from the respiratory tract toward the mouth via the mucociliary escalator (through the movement of microscopic hair-like structures, termed cilia), whereas particles deposited in the alveolar region are cleared primarily by alveolar macrophages through phagocytosis (engulfment) followed by intracellular degradation or transport to the mucociliary escalator. Besides these classical clearance mechanisms, a few other mechanisms of nanoparticle clearance from the lung have been identified, including translocation through the epithelium into the central nervous system by neuronal uptake or into the interstitial space (between the alveoli and lung capillaries), potentially followed by uptake into the lymphatic system or translocation through the vascular endothelium into the blood circulation. ${ }^{17}$ The effects of CNCs upon entering the respiratory tract and their mechanism of clearance from it will depend largely on their degree of aggregation, which determines particle size (and therefore the location of deposition in the respiratory tract) and their surface charge, which governs their interactions with respiratory mucus and cells.

To date, only a few studies have investigated the pulmonary toxicity of CNCs. Yanamala et al. assessed the adverse effects of
CNCs produced by the US Forest Service's Cellulose NanoMaterials Pilot Plant at the Forest Products Laboratory (Madison, WI) in adult female C57BL/6 mice upon pharyngeal aspiration. $^{21}$ The plant produces CNCs from machine-dried prehydrolysis kraft rayon-grade dissolving wood pulp by hydrolysis with $64 \%$ sulfuric acid at $45^{\circ} \mathrm{C}$ for $90 \mathrm{~min}$, followed by dilution, neutralization of the acid with $\mathrm{NaOH}$, and membrane filtration. ${ }^{22}$ It should be noted that the plant's purification process involves the addition of hypochlorite for color removal, which is generally not used in lab-scale methods and might affect the product's toxicity. Two starting materials were tested, a $10 \mathrm{wt} \%$ suspension and a freeze-dried powder. Sterile stock suspensions in USP-grade water of $5-\mathrm{mg} / \mathrm{mL}$ concentration and $\mathrm{pH} 7$ were prepared from the starting materials by dilution, sonication, and autoclaving. The stock suspensions were diluted further, and mice were administered 50, 100 , or $200 \mu \mathrm{g}$ in a volume of approximately $40 \mu \mathrm{L}$. Pharyngeal aspiration is an administration method that involves placement of a liquid sample onto the base of the tongue of the animal and extension of the tongue, resulting in a reflex gasp and aspiration of the liquid. ${ }^{23} \mathrm{~A}$ recent study comparing pharyngeal aspiration to inhalation of single-walled carbon nanotubes found similar outcomes for the two exposure methods. ${ }^{24}$ Yanamala et al. found that both CNC materials elicited dose-dependent oxidative stress, tissue damage, and inflammatory responses. At a dose of $200 \mu \mathrm{g}$, levels of protein carbonyl and 4-hydroxynonenal, two oxidative stress markers, were on average double that of the control, and at least six of the 23 measured markers of inflammation exhibited a more than 10fold increase on CNC administration. Moreover, the extent of the response depended on the starting material. CNCs from the $10 \mathrm{wt} \%$ suspension, having a mean length and width of $90.2 \pm 3.0$ and $7.2 \pm 2.1 \mathrm{~nm}$, respectively (determined by transmission electron microscopy) caused greater increases in oxidative stress markers and inflammatory mediators than freeze-dried CNCs, which have a mean length and width of $207.9 \pm 49.0$ and $8.2 \pm 2.3 \mathrm{~nm}$, respectively, whereas the latter caused a greater increase in biomarkers for tissue damage. The results of Yanamala et al. are in agreement with those of an earlier in vitro study by Clift et al., who assessed the pulmonary toxicity of cotton filter paper-derived CNCs with a threedimensional triple cell coculture model of the human epithelial airway barrier. ${ }^{25}$ Like Yanamala et al., Clift et al. observed a dose-dependent cytotoxicity and (pro-) inflammatory response. At a dose of $0.03 \mathrm{mg} / \mathrm{mL}$, release of the pro-inflammatory chemokine interleukin- 8 by the human bronchial epithelial cellline 16HBE14o- in the triple cell coculture model was about double that of the control.

In a more recent study, O'Connor et al. assessed the acute inhalation toxicity of $\mathrm{NCC}^{\mathrm{TM}}$, a commercial $\mathrm{CNC}$ material manufactured by CelluForce (Montréal, Canada) through hydrolysis of bleached softwood kraft pulp with $64 \%$ sulfuric acid at $45^{\circ} \mathrm{C}$ for $60 \mathrm{~min}^{26}$ The assessment was performed according to test guideline 403 of the Organisation for Economic Cooperation and Development (OECD). Sprague-Dawley stockderived albino rats were exposed by inhalation for a period of $4 \mathrm{~h}$ to aerosolized CNCs at a maximum concentration of $0.26 \mathrm{mg} / \mathrm{L}$ in the exposure chamber and monitored for mortality, gross toxicity, and behavioral changes for a period of $14 \mathrm{~d}$. 


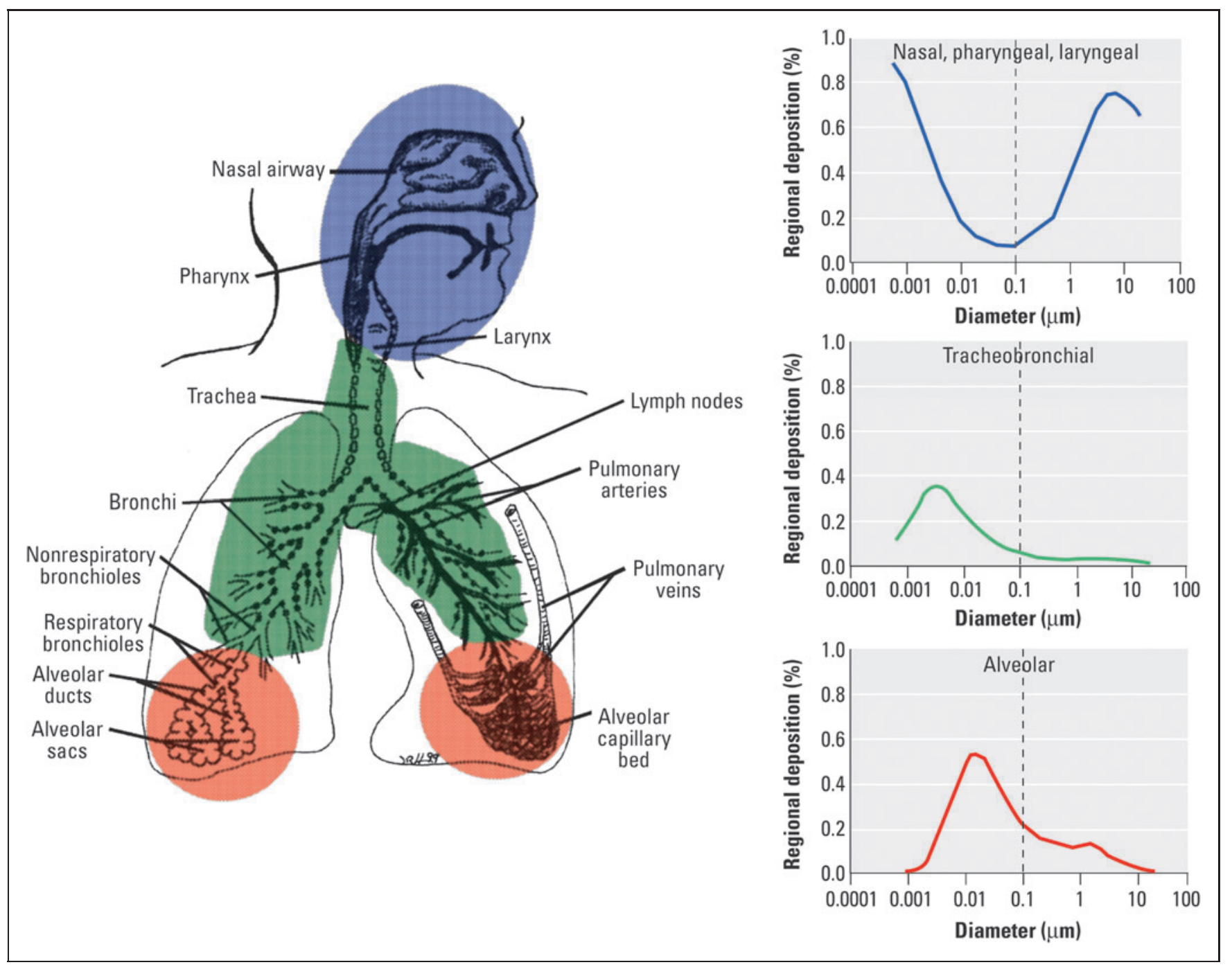

Fig. 2. Predicted fractional deposition of inhaled particles in the nasopharyngeal, tracheobronchial, and alveolar region of the human respiratory tract during nose breathing. Based on data from the International Commission on Radiological Protection. Reproduced with permission from Environmental Health Perspectives. ${ }^{17}$

At the end of the test, all animals were subjected to gross necropsy (animal autopsy). No adverse effects of the aerosolized CNCs on the animals were observed. It should be noted, however, that the study did not involve characterization of the aerosolized CNCs; the properties of the particles inhaled by the rats- the size, shape, and surface charge, in particular-are therefore unknown.

\section{Oral Toxicity}

Oral toxicity is measured in terms of any adverse health effects of a substance entering the orogastrointestinal tract through the mouth. The orogastrointestinal tract comprises the oral cavity, the esophagus, the stomach, and the small and large intestines. Bypassing the oral cavity, an alternative route for substances into the gastrointestinal tract is via clearance from the respiratory tract by the mucociliary escalator. The orogas- trointestinal tract is lined by an epithelium with varying properties along the tract (Table 1). ${ }^{27}$ The orogastrointestinal epithelium is covered by a mucus layer, which contains various proteins, including mucin and antiseptic proteins, such as lysozymes. The thickness of the mucus layer varies from 70 $100 \mu \mathrm{m}$ in the oral cavity to over $1000 \mu \mathrm{m}$ in the stomach, where it is the thickest. ${ }^{27}$ Mucus in the oral cavity has a $\mathrm{pH}$ of about 6.6 , whereas the $\mathrm{pH}$ of stomach mucus ranges from 1-2 at the luminal surface to about 7 at the epithelial surface. The $\mathrm{pH}$ of the intestine changes from 6 in the duodenum, to about 7.4 in the terminal ileum, to 5.7 in the cecum, and to 6.7 in the rectum. ${ }^{28}$

Most studies of nanoparticle uptake by the gastrointestinal tract have shown that nanoparticles pass through the tract and are eliminated from the body in the feces. ${ }^{17}$ However, some studies have demonstrated permeation of the gastrointestinal barrier by micro- and nanoparticles. ${ }^{27}$ In addition, penetration of the buccal mucosa by nanoparticles has recently been shown. ${ }^{29}$ 


\section{ROMAN}

\begin{tabular}{|c|c|c|c|c|}
\hline SECTION & $\begin{array}{l}\text { THICKNESS } \\
(\mu \mathrm{M})\end{array}$ & STRUCTURE & MAIN CELL TYPE & $\begin{array}{l}\text { OTHER CELL } \\
\text { TYPES PRESENT }\end{array}$ \\
\hline Oral cavity & $550-800$ & $\begin{array}{l}\text { Non-keratinized stratified } \\
\text { squamous }\end{array}$ & Keratinocyte & Langerhans, lymphocyte \\
\hline Esophagus & $300-500$ & $\begin{array}{l}\text { Non-keratinized stratified } \\
\text { squamous }\end{array}$ & Keratinocyte & \\
\hline Stomach & $20-25$ & Non-ciliated simple columnar & Gastric epithelial & $\begin{array}{l}\text { Foveolar, gastric chief, } \\
\text { parietal, enteroendocrine }\end{array}$ \\
\hline Small intestine & $20-25$ & Non-ciliated simple columnar & Enterocyte & $\begin{array}{l}\text { Microfold (M-), } \\
\text { enteroendocrine, goblet }\end{array}$ \\
\hline Large intestine & $20-25$ & Non-ciliated simple columnar & Enterocyte & Goblet \\
\hline
\end{tabular}

intestinal epithelium. The passive transcellular transport mechanism (Route 2) involves partitioning into and diffusion across the cell plasma membrane and therefore requires a certain level of lipid solubility. ${ }^{39}$ Hence, CNCs might not be expected to exit the intestine by this mechanism. Active transcellular passage (Route 3 ) occurs either through receptor-mediated or adsorptive-mediated transcytosis, i.e., endocytosis (active cellular uptake) at the apical plasma membrane and exocytosis (expulsion out of the cell) at the basolateral plasma mem-

Particle translocation through a mucous membrane has four components: diffusion through mucus, initial contact with the epithelium, cellular trafficking, and post-translocation events. ${ }^{30}$ A particle's ability to diffuse through mucus depends primarily on its size, surface charge, and hydrophilicity. The main structural component of mucus is a three-dimensional network of mucin, a high molecular weight, highly glycosylated glycoprotein. Smaller particles diffuse more readily through the mucin network than larger particles. Based on a simple cubiclattice model of cylindrical mucin fibers of 3.5-nm radius, the mesh spacing within human cervical mucus has been predicted to be $100 \mathrm{~nm} .{ }^{31}$ The electrostatic properties of mucin are governed by glutamic and aspartic acid residues $\left(\mathrm{p} K_{\mathrm{a}} \approx 4\right)$ in its polypeptide backbone and sialic acid residues $\left(\mathrm{p} K_{\mathrm{a}} \approx 2.6\right)$ and sulfate groups $\left(\mathrm{p} K_{\mathrm{a}} \approx 4\right)$ in its oligosaccharide side chains. The isoelectric point of porcine gastric mucin, which is similar in composition to human mucin, has been determined to lie between $\mathrm{pH} 2$ and $3 .^{32,33}$ In other words, mucin is negatively charged in most sections of the orogastrointestinal tract. As a result of its negative charge, positively charged nanoparticles become entrapped in and diffuse much more slowly through mucus than do negatively charged ones. ${ }^{34}$ For nanoparticles to reach the underlying epithelium, however, they have to penetrate the mucus layer quickly because of its rapid turnover. ${ }^{27}$ In the stomach, mucus is secreted at a rate that makes it unlikely for even the smallest non-mucoadhesive nanoparticles to reach the gastric epithelium. ${ }^{35}$

In the intestine, nanoparticles that penetrate the mucus layer have four possible exit routes through the intestinal epithelium, potentially followed by entry into the lymphatic system or blood circulation (Fig. 3): 1) through direct uptake by M-cells in the Peyer's patches of the gut-associated lymphoid tissue; 2) by passive diffusion through the enterocytes; 3 ) by active transcellular transport; and 4) by paracellular translocation through the tight junctions between the cells. ${ }^{36,37}$ Route 1 has primarily been observed for uncharged hydrophobic particles, whereas Route 4 is restricted to particles with dimensions smaller than the physical dimensions of the paracellular space, estimated to lie between 1 and $3-5 \mathrm{~nm} .{ }^{36,38}$ Neither of these routes is therefore likely to enable significant $\mathrm{CNC}$ translocation through the brane of enterocytes. Adsorptive-mediated transcytosis is facilitated by a positive particle surface charge, giving rise to attractive interactions with anionic sites of the plasma membrane. ${ }^{40}$ Active transcellular transport mechanisms through the intestinal epithelium, however, will play a minor role in the clearance of nanoparticles from the intestinal lumen because of the low endocytic activity of enterocytes. ${ }^{40}$ Consequently, significant permeation of the orogastrointestinal barrier by sulfate group-bearing CNCs is not to be expected.

Only two studies of the oral toxicity of CNCs, both reported by O'Connor et al., have been published to date. ${ }^{26}$ The studies, conducted according to OECD test guidelines 425 and 407, determined acute oral toxicity as well as oral toxicity upon repeated daily administration of NCC, respectively. Acute oral toxicity was assessed by administration of one-time doses of up to $2,000 \mathrm{mg} / \mathrm{kg}$ in aqueous suspension form directly into the stomach of $\mathrm{Crl}: \mathrm{CD}(\mathrm{SD}) \mathrm{BR}$ rats by oral gavage (force feeding) and monitoring of the health of the rats for a period of $14 \mathrm{~d}$ followed by gross necropsy. Using the same rat strain and administration method, the repeated-dose test was performed by daily administration of doses of 500, 1,000, and 2,000 mg/kg for a period of $28 \mathrm{~d}$. During this period, the animals were closely observed for signs of toxicity. At the end of the test, all animals were subjected to gross necropsy. No adverse effects of CNCs on rats were observed and the median lethal dose was established to be above $2,000 \mathrm{mg} / \mathrm{kg}$.

\section{Dermal Toxicity}

Dermal toxicity is measured in terms of any adverse health effects of a substance contacting the skin. Human skin has three layers - the epidermis, dermis, and hypodermis (Fig. 4). Among other functions, the hypodermis thermally insulates the body with adipose tissue, and the dermis provides blood circulation to the epidermis. The main function of the epidermis is to provide a barrier and prevent pathogens from entering the body. The epidermis is a stratified (layered) squamous epithelium, consisting of five strata (Fig. 4). Besides keratinocytes-the main cell type, producing the structural protein keratin-the epidermis contains melanocytes, which produce the skin pigment 


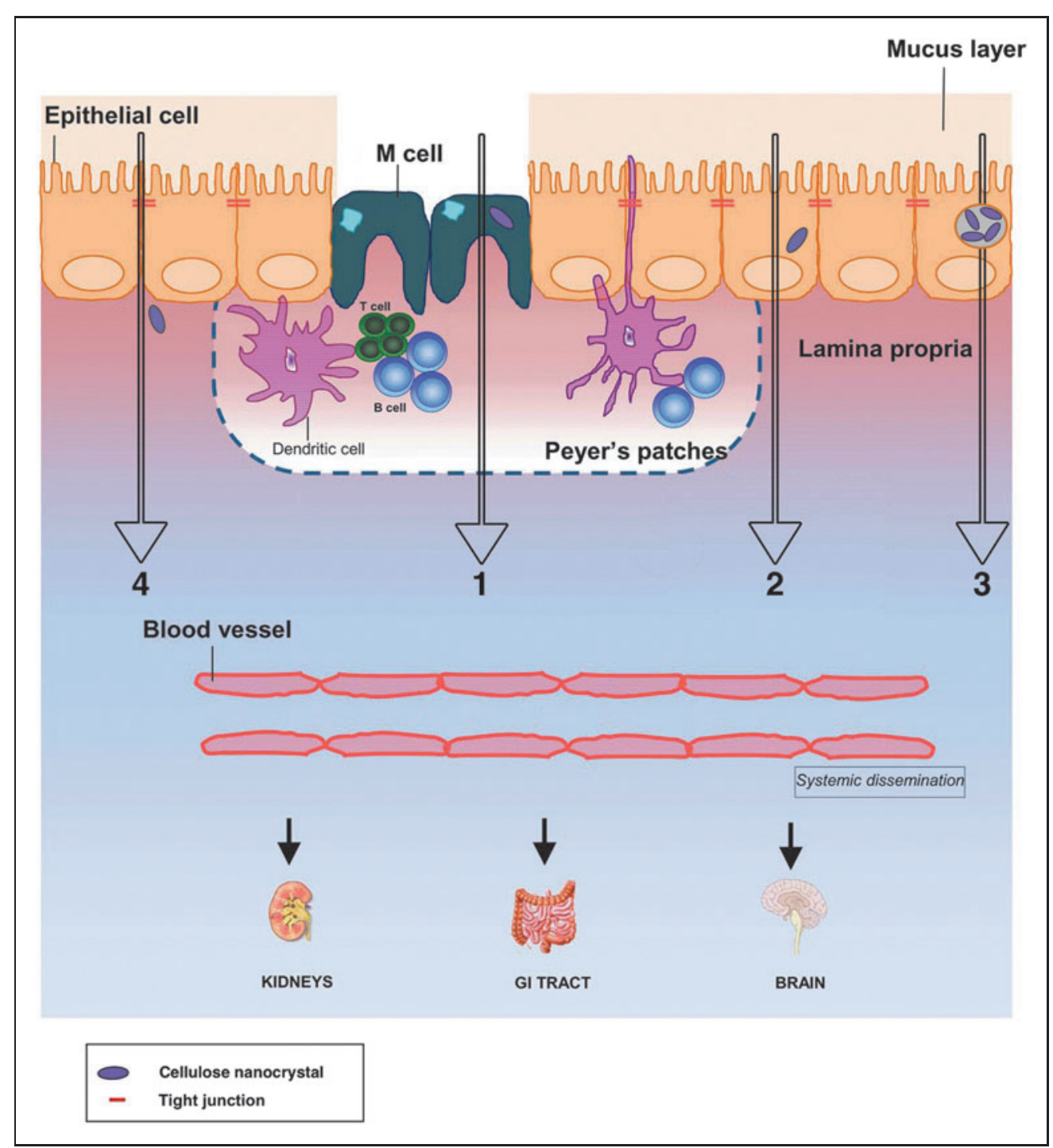

Fig. 3. Possible mechanisms of nanoparticle translocation through the intestinal epithelium: (1) through the M-cells in the Peyer's patches; (2) through enterocytes by passive diffusion; (3) through enterocytes by transcytosis; (4) through the paracellular space. Adapted with permission from Etienne-Mesmin et al. ${ }^{37}$

melanin; Merkel cells, a component of the somatosensory system; and Langerhans cells, which are antigen-presenting immune cells. ${ }^{41}$

For a skin-contacting substance to have an effect on human health, it must first penetrate the stratum corneum, the top-most layer of the epidermis. The stratum corneum is composed of clusters of corneocytes, which are terminally differentiated keratinocytes, embedded in a lipidic matrix. Penetration of the stratum corneum occurs solely by passive diffusion because corneocytes do not possess the ability for active internalization of materials. ${ }^{42}$ Apolar regions in the lipidic matrix potentially enable intercellular diffusion through the stratum corneum of apolar, lipophilic permeates smaller than 5-7 nm, whereas polar regions in the lipidic matrix, termed aqueous pores, potentially enable intercellular diffusion through the stratum corneum of polar, hydrophilic permeates smaller than $36 \mathrm{~nm}^{43}$ The latter pathway, however, may be purely hypothetical because the permeability of the stratum corneum to water molecules has been shown to be very low. ${ }^{44}$ In addition to intercellular diffusion, transcellular diffusion of substances through the corneocytes is possible. This pathway, however, requires repeated partitioning into and out of corneocytes and intracellular and paracellular diffusion through hydrated keratin and the lipidic matrix, respectively. ${ }^{45}$ Another potential skin-penetration route, the transfollicular route, is through epidermal invaginations, such as sweat glands and pilosebaceous units, comprising the hair shaft, hair follicle, sebaceous gland, and arrector pili muscle. ${ }^{43}$ The transfollicular route potentially accommodates permeates up to $210 \mu \mathrm{m}$ in size but requires that they are dispersible in sweat, a dilute aqueous mixture of organic acids, carbohydrates, amino acids, nitrogenous substances, vitamins, and electrolytes; or sebum, a mixture of squalene, waxes, cholesterol derivatives, triglycerides, fatty acids, and cell debris. ${ }^{43}$ As of yet, however, no penetration of skincontacting substances into the sweat glands has been reported. ${ }^{42}$ Furthermore, because of their low density and outward excretions, epidermal invaginations are thought to play a minor role in the dermal absorption of substances. The majority of studies assessing the dermal absorption of nanoparticles reported no unintentional permeation of nanoparticles through the skin. ${ }^{15}$ Accordingly, because of their relatively large size compared to transdermal drug molecules and considerable polar and hydrophilic properties, significant permeation of the dermal barrier by CNCs is not to be expected.

The most common adverse health effect of substances that penetrate the stratum corneum is skin sensitization. ${ }^{46}$ Skin sensitization occurs when a substance that has reached the viable layers of the epidermis, encompassing the stratum granulosum, stratum spinosum, and stratum basale, forms a stable association with skin proteins, triggering dendritic cells to migrate to the lymph nodes and activate T lymphocytes. ${ }^{47}$ O'Connor et al. have assessed the skin-sensitizing potency of CNCs in vivo with the guinea pig maximization test (OECD test guideline 406) and 


\section{ROMAN}

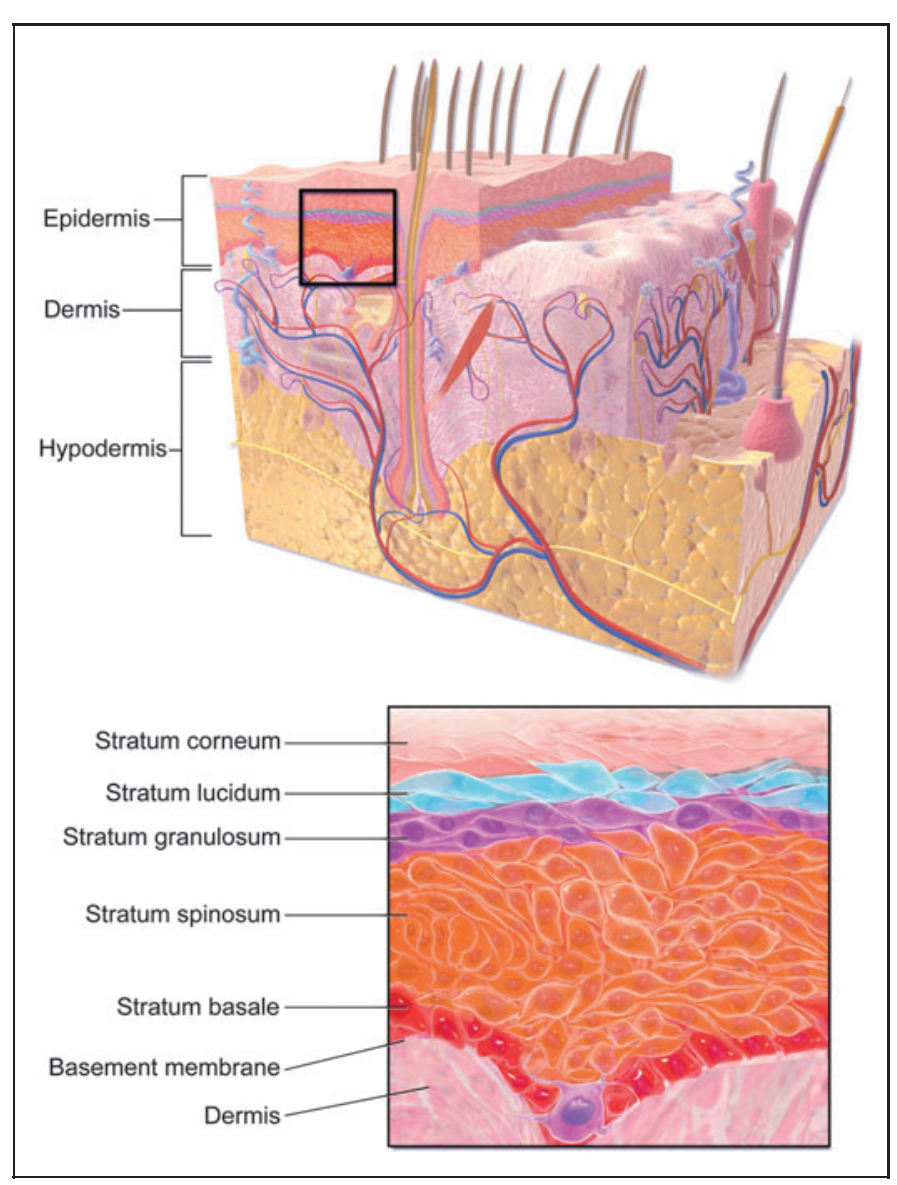

Fig. 4. Structure of the epidermis. Adapted with permission from Blausen gallery 2014, Wikiversity Journal of Medicine.

the murine local lymph node assay (OECD test guideline 429). ${ }^{26}$ In the guinea pig maximization test, $\mathrm{Crl}$ :(HA)BR guinea pigs were exposed to CNCs by intradermal injection of $0.1 \mathrm{~mL}$ of a CNC suspension having a concentration of $1.1 \mathrm{mg} / \mathrm{mL}$. A week later, a CNC gel with a concentration of $103 \mathrm{mg} / \mathrm{mL}$ was applied topically for $48 \mathrm{~h}$ with a filter paper and occlusive dressing. The topical application was repeated two weeks later for $24 \mathrm{~h}$. CNCs were found to be nonsensitizing at the concentrations tested. In the murine local lymph node assay, CBA/J mice were treated for three consecutive days with $25 \mu \mathrm{L}$ of CNC suspension, applied topically to the dorsum of each ear. Three CNC concentrations, ranging from 2.5 to $10.7 \%$, were tested. Three days after the last treatment, proliferation of lymphocytes in the draining auricular lymph nodes, as a measure of dose and potency of the test substance, was determined following euthanasia of the mice injected with a radioactive lymphocyte label and excision and processing of the relevant lymph nodes. On the basis of the test results, CNCs were not considered to be a contact dermal sensitizer at concentrations $\leq 10.7 \%$. In addition to their skinsensitizing potency, O'Connor et al. determined the ability of $\mathrm{CNCs}$ to cause reversible and irreversible skin tissue damage, known as dermal irritation and corrosion, respectively. ${ }^{26}$ In this study, performed according to OECD test guidelines 404 with
Crl:KBL(NZW)BR albino rabbits, a CNC gel containing $0.5 \mathrm{~g}$ of CNCs was applied topically for $4 \mathrm{~h}$ with a gauze patch and semi-occlusive dressing. Following exposure, animals were observed for 14 days and examined for signs of erythema and edema. Skin response was scored on a scale of 0 to 4 at $60 \mathrm{~min}$, $24 \mathrm{~h}, 48 \mathrm{~h}$, and $72 \mathrm{~h}$ after removal of the patch, and the individual scores at each time point were used to calculate the Primary Irritation Index. No corrosive effects were observed and the material $(\mathrm{NCC})$ scored a Primary Irritation Index of 0 (nonirritating).

\section{Cytotoxicity}

Cytotoxicity refers to adverse effects of a substance on cell viability. Evaluation methods of cytotoxicity can be grouped into four categories: 1) methods that assess cell damage on the basis of cell morphology; 2) methods that measure cell damage; 3) methods that measure cell growth; and 4) methods that measure specific metabolic activities. A number of research teams have conducted cytotoxicity studies with CNCs. The reports available in the literature to date are summarized in Table 2. ${ }^{25,48-57}$ Most studies showed CNCs to have no cytotoxic effects, as defined by ISO standard 10993-5, i.e., not to reduce cell viability by more than $30 \%$. However, several studies found a dose dependency of CNC cytotoxicity. ${ }^{25,49,53,56,57}$ The most pronounced decrease in cell viability was reported by Kovacs et al., who reported a decrease in rainbow trout hepatocyte viability of $20 \%$ at an estimated CNC concentration of $0.034 \mathrm{mg} /$ $\mathrm{mL}$ and a decrease of $50 \%$, i.e., cytotoxic effects at an estimated concentration of $0.245 \mathrm{mg} / \mathrm{mL} .{ }^{49}$ The results of Kovacs et al. are in stark contrast to the findings of a more recent study by Zoppe et al., who reported human corneal epithelial cell viabilities in excess of $90 \%$ at a CNC concentration of $0.1 \%(\sim 1 \mathrm{mg} / \mathrm{mL}) .{ }^{56}$ The discrepancies in the results of current CNC cytotoxicity studies are not surprising, however, considering that they all used different cell lines, cellulose sources, CNC preparation procedures, and post-processing or sample preparation methods (Table 2).

Different cellulose sources, preparation procedures, and postprocessing methods, such as sonication, will obviously yield CNCs with different physicochemical properties, and CNCs with different particle dimensions and surface chemistries will likely have different effects on cell viability. Most studies, therefore, include $\mathrm{CNC}$ characterization to some extent. It is important to note, however, that post-processing methods such as autoclaving may alter the physicochemical properties of CNCs, making it critical to determine these properties in the final samples. A frequently overlooked factor is that cellulose sources sometimes contain endotoxins or cytotoxic chemicals from prior processing, such as pulping, that could affect cell viability. In addition, the $\mathrm{CNC}$ preparation or post processing procedures themselves might introduce cytotoxic impurities into the material. For example, heating of sulfate group-bearing $\mathrm{CNCs}$, as done during autoclaving, is known to cause desulfation and the release of sulfuric acid from the CNC surface. ${ }^{58}$ In ISO standard 10993-12, residues from the manufacturing process are considered integral to the medical device under evaluation. However, if one is interested in the cytotoxicity of CNCs 
Table 2. Current CNC Cytotoxicity Studies

\section{CELLULOSE SOURCE}

Dissolving-grade softwood sulfite pulp

\begin{tabular}{|c|c|}
\hline $\begin{array}{l}\text { Dissolving-grade } \\
\text { softwood sulfite pulp }\end{array}$ & $\begin{array}{l}64 \mathrm{wt} \% \mathrm{H}_{2} \mathrm{SO}_{4}, 45^{\circ} \mathrm{C}, \\
60 \mathrm{~min}, 10 \mathrm{~mL} / \mathrm{g}\end{array}$ \\
\hline Bleached kraft pulp & $N A^{c}$ \\
\hline
\end{tabular}

\begin{tabular}{l} 
\\
\hline Eucalyptus wood pulp \\
\hline Bleached softwood pulp \\
\hline $\begin{array}{l}\text { Whatman No. } 1 \text { filter } \\
\text { paper (cotton) }\end{array}$ \\
\hline $\begin{array}{l}\text { Avicel PH-101, Whatman } \\
\text { CF1 cellulose powder, flax } \\
\text { pectate lyase-treated flax } \\
\text { hemp, pectate lyase- } \\
\text { treated hemp }\end{array}$ \\
\hline
\end{tabular}

\begin{tabular}{|c|c|c|c|c|c|}
\hline $\begin{array}{l}\text { hectate lyase-treated flax, } \\
\text { hemp, pectate lyase- } \\
\text { treated hemp }\end{array}$ & 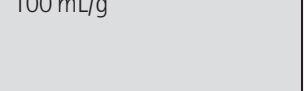 & 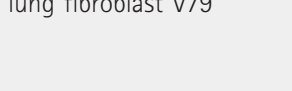 & 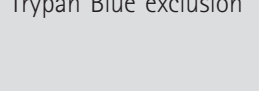 & & \\
\hline Cotton linters & $\begin{array}{l}50 \mathrm{wt} \% \mathrm{H}_{2} \mathrm{SO}_{4}, 45^{\circ} \mathrm{C}, 56 \mathrm{~h}, \\
\text { NA }\end{array}$ & L929 & MTT & $0.01-1 \%, 24 \mathrm{~h}$ & $\begin{array}{l}\text { CNCs have dose- } \\
\text { dependent cytotoxicity, } \\
\text { which is low at } \\
\text { concentrations below } \\
0.2 \% \%^{53}\end{array}$ \\
\hline $\begin{array}{l}\text { Dissolving-grade } \\
\text { softwood sulfite pulp }\end{array}$ & $\begin{array}{l}64 \mathrm{wt} \% \mathrm{H}_{2} \mathrm{SO}_{4}, 45^{\circ} \mathrm{C}, \\
60 \mathrm{~min}, 10 \mathrm{~mL} / \mathrm{g}\end{array}$ & $\begin{array}{l}\text { Human brain } \\
\text { microvascular endothelial, } \\
\text { bEnd.3, RAW 264.7, MCF- } \\
\text { 10A, MDA-MB-231, MDA- } \\
\text { MB-468, KB, PC-3, C6 }\end{array}$ & MTT and LDH & $0.01-0.05 \mathrm{mg} / \mathrm{mL}, 48 \mathrm{~h}$ & $\begin{array}{l}\text { CNCs are non-toxic to a } \\
\text { variety of mammalian cells } s^{54}\end{array}$ \\
\hline $\begin{array}{l}\text { Whatman cotton ashless } \\
\text { filter aid }\end{array}$ & $\begin{array}{l}64 \mathrm{wt} \% \mathrm{H}_{2} \mathrm{SO}_{4}, 45^{\circ} \mathrm{C}, \\
45 \mathrm{~min}, \mathrm{NA}\end{array}$ & NIH 3 T3 fibroblast & MTT & $0.1-1 \mathrm{mg} / \mathrm{mL}, 24 \mathrm{~h}$ & $\begin{array}{l}\text { CNCs have no significant } \\
\text { cytotoxicity }^{55}\end{array}$ \\
\hline $\begin{array}{l}\text { Cotton fibers and } \\
\text { Whatman } 1 \text { filter paper }\end{array}$ & $\begin{array}{l}65 \text { wt } \% \mathrm{H}_{2} \mathrm{SO}_{4}, 45^{\circ} \mathrm{C} \\
45 \mathrm{~min}, \mathrm{NA}\end{array}$ & Human corneal epithelial & CellTiter Blue & $0.1-0.4 \%, 1 \mathrm{~h}$ & $\begin{array}{l}\text { Sulfate group-bearing } \\
\text { CNCs have a negligible } \\
\text { effect on cell viability } \\
(\geq 80 \% \text { of control at } \\
0.4 \%) \text {, whereas that of } \\
\text { desulfated cotton CNCs is } \\
\text { considerable }(<70 \% \text { of } \\
\text { control at } 0.4 \%)^{56}\end{array}$ \\
\hline Avicel PH-101 & acid, $^{d} 50^{\circ} \mathrm{C}, 180 \mathrm{~min}, \mathrm{NA}$ & $\begin{array}{l}\text { NIH3T3 murine embryo } \\
\text { fibroblast, HCT116 colon } \\
\text { adenocarcinoma }\end{array}$ & WST-1 & $0.01-1 \mathrm{mg} / \mathrm{mL}$ & $\begin{array}{l}\text { CNCs are not cytotoxic at } \\
\text { concentrations of or } \\
\text { below } 0.25 \mathrm{mg} / \mathrm{mL} \text { but } \\
\text { exhibit significant } \\
\text { cytotoxic effects at } \\
\text { concentrations of or } \\
\text { above } 0.5 \mathrm{mg} / \mathrm{mL}^{57}\end{array}$ \\
\hline
\end{tabular}

CONCENTRATION,

EXPOSURE TIME

STUDY

FINDINGS $^{\mathrm{b}}$

$0.01-0.05 \mathrm{mg} / \mathrm{mL}$, 24-72 h

CNCs are non-toxic to human brain microvascular endothelial cells ${ }^{48}$

CNCs reduce cell viability and have an estimated EC20 and EC50 of 0.034 and $0.245 \mathrm{mg} / \mathrm{mL}$, respectively ${ }^{49}$ proteins, lipid peroxidation, DNA precipitation assay

CNCs have no significant effect on cell viability ${ }^{50}$

CNCs have no lytic effect $^{51}$

$\mathrm{LDH}$, tumor necrosis factor- $\alpha$, interleukin-8, electron tomography human bronchial epithelia (16HBE140-)

Spodoptera frugiperda Sf9 insect, Chinese hamster lung fibroblast V79

Electric cell-substrate impedance sensing and

$0.01-0.2 \mathrm{mg} / \mathrm{mL}, 5-22 \mathrm{~h}$

Trypan Blue exclusion

0.005-0.03 mg/mL, $24 \mathrm{~h} \quad$ CNCs elicit a dose-
dependent cytotoxicity and (pro-)inflammatory response $\mathrm{e}^{25}$

CNCs are not significantly cytotoxic $^{52}$ solution, $60^{\circ} \mathrm{C}, 16 \mathrm{~h}$ $100 \mathrm{~mL} / \mathrm{g}$

and

(1)

cyto

\begin{tabular}{|l|l|l}
$\begin{array}{l}\text { Fluorescein dye retention } \\
\text { assay, labile zinc, cell } \\
\text { carbohydrates, heat shock } \\
\text { proteins, lipid }\end{array}$ & $0-2 \mathrm{mg} / \mathrm{mL}, 48 \mathrm{~h}$ & $\begin{array}{l}\mathrm{CNC} \text { reduce cell viability } \\
\text { and have an estimated } \\
\text { EC20 and } \mathrm{EC} 50 \text { of } 0.034 \\
\text { and } 0.245 \mathrm{mg} / \mathrm{mL},\end{array}$
\end{tabular}

\begin{tabular}{|c|c|c|c|c|c|}
\hline $\begin{array}{l}\text { pectate lyase-treated flax, } \\
\text { hemp, pectate lyase- } \\
\text { treated hemp }\end{array}$ & $100 \mathrm{~mL} / \mathrm{g}$ & lung fibroblast V79 & Trypan Blue exclusion & & \\
\hline Cotton linters & $\begin{array}{l}50 \mathrm{wt} \% \mathrm{H}_{2} \mathrm{SO}_{4}, 45^{\circ} \mathrm{C}, 56 \mathrm{~h}_{1} \\
\mathrm{NA}\end{array}$ & L929 & MTT & $0.01-1 \%, 24 \mathrm{~h}$ & $\begin{array}{l}\text { CNCs have dose- } \\
\text { dependent cytotoxicity, } \\
\text { which is low at } \\
\text { concentrations below } \\
0.2 \% \%^{53}\end{array}$ \\
\hline $\begin{array}{l}\text { Dissolving-grade } \\
\text { softwood sulfite pulp }\end{array}$ & $\begin{array}{l}64 \mathrm{wt} \% \mathrm{H}_{2} \mathrm{SO}_{4}, 45^{\circ} \mathrm{C}, \\
60 \mathrm{~min}, 10 \mathrm{~mL} / \mathrm{g}\end{array}$ & $\begin{array}{l}\text { Human brain } \\
\text { microvascular endothelial, } \\
\text { bEnd.3, RAW 264.7, MCF- } \\
\text { 10A, MDA-MB-231, MDA- } \\
\text { MB-468, KB, PC-3, C6 }\end{array}$ & MTT and LDH & $0.01-0.05 \mathrm{mg} / \mathrm{mL}, 48 \mathrm{~h}$ & $\begin{array}{l}\text { CNCs are non-toxic to a } \\
\text { variety of mammalian cells } 5^{54}\end{array}$ \\
\hline $\begin{array}{l}\text { Whatman cotton ashless } \\
\text { filter aid }\end{array}$ & $\begin{array}{l}64 \mathrm{wt} \% \mathrm{H}_{2} \mathrm{SO}_{4}, 45^{\circ} \mathrm{C}, \\
45 \mathrm{~min}, \mathrm{NA}\end{array}$ & NIH 3 T3 fibroblast & MTT & $0.1-1 \mathrm{mg} / \mathrm{mL}, 24 \mathrm{~h}$ & $\begin{array}{l}\text { CNCs have no significant } \\
\text { cytotoxicity }\end{array}$ \\
\hline $\begin{array}{l}\text { Cotton fibers and } \\
\text { Whatman } 1 \text { filter paper }\end{array}$ & $\begin{array}{l}65 \mathrm{wt} \% \mathrm{H}_{2} \mathrm{SO}_{4}, 45^{\circ} \mathrm{C}, \\
45 \mathrm{~min}, \mathrm{NA}\end{array}$ & Human corneal epithelial & CellTiter Blue & $0.1-0.4 \%, 1 \mathrm{~h}$ & $\begin{array}{l}\text { Sulfate group-bearing } \\
\text { CNCs have a negligible } \\
\text { effect on cell viability } \\
(\geq 80 \% \text { of control at } \\
0.4 \%) \text {, whereas that of } \\
\text { desulfated cotton CNCs is } \\
\text { considerable }(<70 \% \text { of } \\
\text { control at } 0.4 \%)^{56}\end{array}$ \\
\hline Avicel PH-101 & $\operatorname{acid}{ }^{d} 50^{\circ} \mathrm{C}, 180 \mathrm{~min}, \mathrm{NA}$ & $\begin{array}{l}\text { NIH3T3 murine embryo } \\
\text { fibroblast, HCT116 colon } \\
\text { adenocarcinoma }\end{array}$ & WST-1 & $0.01-1 \mathrm{mg} / \mathrm{mL}$ & $\begin{array}{l}\text { CNCs are not cytotoxic at } \\
\text { concentrations of or } \\
\text { below } 0.25 \mathrm{mg} / \mathrm{mL} \text { but } \\
\text { exhibit significant } \\
\text { cytotoxic effects at } \\
\text { concentrations of or } \\
\text { above } 0.5 \mathrm{mg} / \mathrm{mL}^{57}\end{array}$ \\
\hline
\end{tabular}

\footnotetext{
aReagent, reaction temperature, reaction time, reagent-to-cellulose ratio.

${ }^{b}$ For the experimental conditions used.

'NA, not available.

dg $\mathrm{M} \mathrm{H}_{2} \mathrm{SO}_{4}, 3: 1(\mathrm{v} / \mathrm{v})$ mixture of $18 \mathrm{M} \mathrm{H}_{2} \mathrm{SO}_{4}$ and $12 \mathrm{M} \mathrm{HCl}_{\text {, or }} 12 \mathrm{M} \mathrm{HCl}$.

(9 $\mathrm{M} \mathrm{H}_{2} \mathrm{SO}_{4} 3: 1\left(\mathrm{v} / \mathrm{V}\right.$ mixture of $18 \mathrm{M} \mathrm{H}_{2} \mathrm{SO}_{4}$ and $12 \mathrm{M} \mathrm{HCl}$, or $12 \mathrm{M} \mathrm{HCl}$.
}

\section{CNC}




\section{ROMAN}

per se, as opposed to a commercial product, the interfering effects of endotoxins and cytotoxic contaminants need to be eliminated through the use of suitable blanks. In addition, as mentioned in the introduction, the acidic or $\mathrm{pH}$-lowering properties of CNCs need to be considered. A significant decrease in the culture medium's $\mathrm{pH}$ on $\mathrm{CNC}$ addition could negatively affect cell viability. If the $\mathrm{pH}$-lowering effect of CNCs is to be excluded from the study, their sodium salt form should be used. Last but not least, the degree of aggregation or dispersion of the $\mathrm{CNCs}$ in the cell culture medium needs to be assessed for accurate information on the particle size to which the cells are being exposed. Needless to say, all of these factors (presence of cytotoxic impurities and design of test blanks, effect of CNCs on medium $\mathrm{pH}$ or use of the sodium salt form, and aggregation of CNCs in the culture medium) need to be carefully addressed in the report of the study. Of the reports listed in Table 2, only two considered the effects of CNC acidity and aggregation, and several of the reports failed to describe the methods of cell exposure or sample sterilization in sufficient detail to allow evaluation of their potential effects on the test results. ${ }^{52,54}$ Future CNC cytotoxicity studies should address all of the abovementioned factors to allow correlation of their results.

\section{Conclusions}

Current studies of the oral and dermal toxicity of CNCs have shown a lack of adverse health effects. The available studies, however, are still very limited in number (two oral toxicity studies and three dermal toxicity studies) and in the variety of tested CNC materials (CelluForce's NCC). Additional oral and dermal toxicity studies are needed to support the general conclusion that CNCs are nontoxic upon ingestion or contact with the skin. Studies of pulmonary and cytotoxicity, on the other hand, have yielded discordant results. The questions of whether CNCs have adverse health effects on inhalation and whether they elicit inflammatory or oxidative stress responses at the cellular level therefore warrant further investigation. The toxicity of CNCs will depend strongly on their physicochemical properties - in particular, surface chemistry, including particle charge, and degree of aggregation, which determines particle shape and dimensions. Therefore, these properties-which in turn depend strongly on the cellulose source, CNC preparation procedure, and post-processing or sample preparation methods, such as lyophilization, aerosolization, sonication, or sterilizationneed to be carefully measured in the final samples.

Another factor that might affect the outcomes of toxicity studies are sample contaminants, such as endotoxins or toxic chemical impurities. Samples for exposure tests should therefore be carefully analyzed for such contaminants prior to testing. Ideally, because detection of toxic chemical contaminants may be difficult, control experiments should be carried out with suitable blanks from which the CNCs have been removed, for example by membrane filtration. Moreover, especially in cytotoxicity assessments, the effect of CNCs on $\mathrm{pH}$ and their aggregation in the cell culture medium need to be monitored. Only by careful particle characterization and exclusion of interfering factors will we be able to develop a detailed understanding of the potential adverse health effects of CNCs.

\section{Acknowledgments}

Funding for this work was provided in part by the Virginia Agricultural Experiment Station (Blacksburg, VA) and the Hatch Multistate Program of the National Institute of Food and Agriculture, US Department of Agriculture.

\section{Author Disclosure Statement}

No competing financial interests exist.

\section{REFERENCES}

1. Moon RJ, Martini A, Nairn J, et al. Cellulose nanomaterials review: Structure, properties and nanocomposites. Chem Soc Rev 2011;40(7):3941-3994.

2. Wang Q0, Zhu JY, Considine JM. Strong and optically transparent films prepared using cellulosic solid residue recovered from cellulose nanocrystals production waste stream. ACS Appl Mater Interfaces 2013; 5(7):2527-2534.

3. Lagerwall JPF, Schutz C, Salajkova M, et al. Cellulose nanocrystal-based materials: From liquid crystal self-assembly and glass formation to multifunctional thin films. NPG Asia Mater 2014;6:e80.

4. Klemm D, Kramer F, Moritz $S$, et al. Nanocelluloses: A new family of naturebased materials. Angew Chem Int Ed Engl 2011;50(24):5438-5466.

5. Plackett DV, Letchford K, Jackson JK, Burt HM. A review of nanocellulose as a novel vehicle for drug delivery. Nord Pulp Pap Res J 2014;29(1):105-118.

6. Dong S, Cho HJ, Lee YW, Roman M. Synthesis and cellular uptake of folic acidconjugated cellulose nanocrystals for cancer targeting. Biomacromolecules 2014;15(5):1560-1567.

7. Czaja WK, Young DJ, Kawecki M, Brown RM. The future prospects of microbial cellulose in biomedical applications. Biomacromolecules 2007;8(1):1-12.

8. Lin N, Dufresne A. Nanocellulose in biomedicine: Current status and future prospect. Eur Polym J 2014;59:302-325.

9. Jorfi M, Foster EJ. Recent advances in nanocellulose for biomedical applications. J Appl Polym Sci 2015;41719.

10. Siqueira G, Bras J, Dufresne A. Cellulosic bionanocomposites: A review of preparation, properties and applications. Polymers 2010;2:728-765.

11. Habibi Y, Lucia LA, Rojas OJ. Cellulose nanocrystals: Chemistry, self-assembly, and applications. Chem Rev 2010;110(6):3479-3500.

12. Beck-Candanedo S, Roman M, Gray DG. Effect of reaction conditions on the properties and behavior of wood cellulose nanocrystal suspensions. Biomacromolecules 2005;6(2):1048-1054.

13. Wang $\mathrm{H}$, Qian $\mathrm{C}$, Roman $\mathrm{M}$. Effects of $\mathrm{pH}$ and salt concentration on the formation and properties of chitosan-cellulose nanocrystal polyelectrolytemacroion complexes. Biomacromolecules 2011;12(10):3708-3714.

14. Elsaesser A, Howard CV. Toxicology of nanoparticles. Adv Drug Deliv Rev 2012;64(2):129-137.

15. Landsiedel R, Fabian $E$, Ma-Hock $L$, et al. Toxico-/biokinetics of nanomaterials. Arch Toxicol 2012;86(7):1021-1060.

16. Human respiratory tract model for radiological protection. A report of a task group of the international commission on radiological protection. Ann ICRP 1994;24(1-3):1-482.

17. Oberdörster G, Oberdörster E, Oberdörster J. Nanotoxicology: An emerging discipline evolving from studies of ultrafine particles. Environ Health Perspect 2005;113(7):823-839.

18. Kaliner M, Shelhamer JH, Borson B, et al. Human respiratory mucus. Am Rev Respir Dis 1986;134(3):612-621.

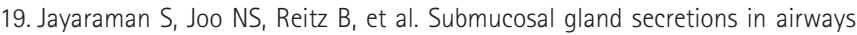
from cystic fibrosis patients have normal $\left[\mathrm{Na}^{+}\right]$and $\mathrm{pH}$ but elevated viscosity. Proc Natl Acad Sci 2001;98(14):8119-8123. 


\section{TOXICITY OF CELLULOSE NANOCRYSTALS}

20. Siebert TA, Rugonyi S. Influence of liquid-layer thickness on pulmonary surfactant spreading and collapse. Biophys J 2008;95(10):4549-4559.

21. Yanamala N, Farcas MT, Hatfield MK, et al. In vivo evaluation of the pulmonary toxicity of cellulose nanocrystals: A renewable and sustainable nanomaterial of the future. ACS Sustain Chem Eng 2014;2(7):1691-1698.

22. Reiner RS, Rudie AW. Process scale-up of cellulose nanocrystal production to $25 \mathrm{~kg}$ per batch at the forest products laboratory. In: Postek MT, Moon RJ, Rudie AW, Bilodeau MA, eds. Production and Applications of Cellulose Nanomaterials. Peachtree Corners, GA: TAPPI Press, 2013:21-24.

23. Rao GVS, Tinkle $S$, Weissman $D$, et al. Efficacy of a technique for exposing the mouse lung to particles aspirated from the pharynx. J Toxicol Environ Health A 2003;66(15-16):1441-1452

24. Shvedova AA, Kisin E, Murray $A R$, et al. Inhalation vs. aspiration of singlewalled carbon nanotubes in c57bl/6 mice: Inflammation, fibrosis, oxidative stress, and mutagenesis. Am J Physiol Lung Cell Mol Physiol 2008;295(4): L552-L565.

25. Clift MJD, Foster EJ, Vanhecke D, et al. Investigating the interaction of cellulose nanofibers derived from cotton with a sophisticated 3D human lung cell coculture. Biomacromolecules 2011;12(10):3666-3673.

26. O'Connor B, Berry R, Goguen R. Chapter 10-Commercialization of cellulose nanocrystal (NCC ${ }^{\mathrm{TM}}$ ) production: A business case focusing on the importance of proactive ehs management. In: Hull MS, Bowman DM, eds. Nanotechnology Environmental Health and Safety (Second Edition). Oxford: William Andrew Publishing, 2014:225-246.

27. Fröhlich $E$, Roblegg E. Models for oral uptake of nanoparticles in consumer products. Toxicology 2012;291(1-3):10-17.

28. Fallingborg J. Intraluminal $\mathrm{pH}$ of the human gastrointestinal tract. Dan Med Bull 1999;46(3):183-196.

29. Roblegg $E$, Fröhlich $E_{1}$ Meindl $C$, et al. Evaluation of a physiological in vitro system to study the transport of nanoparticles through the buccal mucosa. Nanotoxicology 2012;6(4):399-413.

30. Hussain N, Jaitley V, Florence AT. Recent advances in the understanding of uptake of microparticulates across the gastrointestinal lymphatics. Adv Drug Delivery Rev 2001;50(1-2):107-142.

31. Olmsted SS, Padgett JL, Yudin Al, et al. Diffusion of macromolecules and viruslike particles in human cervical mucus. Biophys J 2001;81(4):1930-1937.

32. Montagna W. Comparative Anatomy. New York: Wiley, 1959.

33. Lee $S$, Muller M, Rezwan $K$, Spencer ND. Porcine gastric mucin (PGM) at the water/poly(dimethylsiloxane) (PDMS) interface: Influence of $\mathrm{pH}$ and ionic strength on its conformation, adsorption, and aqueous lubrication properties. Langmuir 2005;21(18):8344-8353.

34. Crater JS, Carrier RL. Barrier properties of gastrointestinal mucus to nanoparticle transport. Macromol Biosci 2010;10(12):1473-1483.

35. Cone RA. Barrier properties of mucus. Adv Drug Delivery Rev 2009;61(2):75-85.

36. Florence $A$. The oral absorption of micro- and nanoparticulates: Neither exceptional nor unusual. Pharm Res 1997;14(3):259-266.

37. Etienne-Mesmin $L$, Chassaing $B$, Sauvanet $P$, et al. Interactions with $M$ cells and macrophages as key steps in the pathogenesis of enterohemorragic Escherichia coli infections. PLoS One 2011;6(8):e23594.

38. Nellans HN. (B) Mechanisms of peptide and protein absorption: (1) Paracellular intestinal transport: Modulation of absorption. Adv Drug Delivery Rev $1991 ; 7(3): 339-364$.

39. Burton PS, Conradi RA, Hilgers AR. (B) Mechanisms of peptide and protein absorption: (2) Transcellular mechanism of peptide and protein absorption: Passive aspects. Adv Drug Delivery Rev 1991;7(3):365-385.

40. Harush-Frenkel O, Rozentur E, Benita S, Altschuler Y. Surface charge of nanoparticles determines their endocytic and transcytotic pathway in polarized MDCK cells. Biomacromolecules 2008;9(2):435-443.
41. Maricich SM, Wellnitz SA, Nelson AM, et al. Merkel cells are essential for lighttouch responses. Science 2009;324(5934):1580-1582.

42. Schaefer $H_{1}$ Redelmeier $T$, Lademann J. Skin penetration. In: Johansen JD, Frosch PJ, Lepoittevin J-P, eds. Contact Dermatitis. Springer: Berlin Heidelberg, 2011:215-227.

43. Baroli B. Penetration of nanoparticles and nanomaterials in the skin: Fiction or reality? J Pharm Sci 2010;99(1):21-50.

44. Potts RO, Francoeur ML. The influence of stratum corneum morphology on water permeability. J Investig Dermatol 1991;96(4):495-499.

45. Williams AC. Transdermal and Topical Drug Delivery. London, UK: Pharmaceutical Press; 2003.

46. Kimber I, Basketter DA, Gerberick GF, et al. Chemical allergy: Translating biology into hazard characterization. Toxicol Sci 2011;120(suppl 1):S238-S268.

47. Basketter D, Casati S. Dermal toxicity: Skin sensitization. In: Bal-Price $A$, Jennings P, eds. In Vitro Toxicology Systems. Springer: New York, 2014:225-239.

48. Roman M, Dong S, Hirani A, Lee YW. Cellulose nanocrystals for drug delivery. In: Edgar KJ, Heinze T, Buchanan CM, eds. Polysaccharide Materials: Performance by Design. Washington, DC: American Chemical Society, 2009:81-91.

49. Kovacs T, Naish $V$, O'Connor B, et al. An ecotoxicological characterization of nanocrystalline cellulose (NCC). Nanotoxicology 2010;4(3):255-270.

50. Villanova JCO, Ayres E, Carvalho SM, et al. Pharmaceutical acrylic beads obtained by suspension polymerization containing cellulose nanowhiskers as excipient for drug delivery. Eur J Pharm Sci 2011;42(4):406-415.

51. Jackson JK, Letchford $K$, Wasserman BZ, et al. The use of nanocrystalline cellulose for the binding and controlled release of drugs. Int J Nanomedicine 2011;6:321-330

52. Male KB, Leung ACW, Montes J, et al. Probing inhibitory effects of nanocrystalline cellulose: Inhibition versus surface charge. Nanoscale 2012;4(4):1373-1379.

53. Ni H, Zeng $\mathrm{S}, \mathrm{Wu}$ J, et al. Cellulose nanowhiskers: Preparation, characterization and cytotoxicity evaluation. Biomed Mater Eng 2012;22(1-3):121-127.

54. Dong $S$, Hirani AA, Colacino KR, et al. Cytotoxicity and cellular uptake of cellulose nanocrystals. Nano Life 2012;2(3):1241006.

55. Yang $X$, Bakaic E, Hoare T, Cranston ED. Injectable polysaccharide hydrogels reinforced with cellulose nanocrystals: Morphology, rheology, degradation, and cytotoxicity. Biomacromolecules 2013;14(12):4447-4455.

56. Zoppe JO, Ruottinen V, Ruotsalainen J, et al. Synthesis of cellulose nanocrystals carrying tyrosine sulfate mimetic ligands and inhibition of alphavirus infection. Biomacromolecules 2014;15(4):1534-1542.

57. Hanif Z, Ahmed FR, Shin SW, et al. Size- and dose-dependent toxicity of cellulose nanocrystals (CNC) on human fibroblasts and colon adenocarcinoma. Colloids Surf B Biointerfaces 2014;119:162-165.

58. Beck S, Bouchard J. Auto-catalyzed acidic desulfation of cellulose nanocrystals. Nord Pulp Pap Res J 2014;29(1):006-014.

Address correspondence to: Maren Roman, PhD Associate Professor Department of Sustainable Biomaterials Virginia Tech

Cheatham Hall, STE 230 310 West Campus Dr. Blacksburg, VA 24061

Phone: (540) 231-1421

Fax: (540) 231-8176

E-mail: maren.roman@vt.edu 